\title{
A DIMENSÃO DIALÓGICA, ESTÉTICA, FORMATIVA E ÉTICA DA MEDIAÇÃOO DA INFORMAÇÃO
}

\section{DIMENSION DIALÓGICA, ESTÉTICA, FORMATIVA Y ÉTICA DE LA MEDIACIÓN DE LA INFORMACIÓN}

\begin{abstract}
Henriette Ferreira Gomes - henriettefgomes@gmail.com Doutora em Educação pela Universidade Federal da Bahia (UFBA). Professora Titular do Instituto de Ciência da Informação e do Programa de Pós-Graduação em Ciência da Informação da UFBA.
\end{abstract}

RESUMO

Introdução: Aborda a mediação da informação a partir do seu objetivo implícito de atuar no desenvolvimento do protagonismo social.

Objetivo: Ampliar o debate e as reflexões em torno das dimensões dialógica, estética, formativa e ética da mediação da informação.

Metodologia: Caracteriza-se como estudo bibliográfico a partir da associação de obras que focalizam as temáticas consciência, estética, educação e ética, com outras já adotadas na literatura da área para tratar da mediação da informação.

Resultados: As dimensões dialógica, estética, formativa e ética da mediação da informação se apresentam como tópicos temáticos para o aprofundamento dos estudos da área.

Conclusão: A mediação da informação caracteriza-se como uma ação dependente do processo dialógico e do nível de conscientização do mediador quanto ao seu próprio papel protagonista. Assim, o estudo dessas dimensões pode fazer avançar o aporte teórico para o desenvolvimento de novas experiências no âmbito da ação mediadora do acesso, uso e apropriação a informação, voltada à formação do protagonismo social.

Palavras-chave: Mediação da informação - Estética. Mediação da informação Ética. Mediação da informação - Formação do usuário. Mediação da informação Dialogismo. 


\section{INTRODUÇÃO}

A mediação da informação ganha cada vez mais destaque nas discussões epistemológicas da Ciência da Informação. A persistência de pesquisadores da área em aprofundar estudos acerca dessa temática tem mobilizado a atenção, inclusive, dos atores envolvidos com a formação dos profissionais que trabalham diretamente com a informação.

De modo central esses estudos têm se ocupado da abordagem conceitual, dos fundamentos teóricos, do delineamento dos tipos de mediação, das categorias de atividades de mediação e do papel mediador do profissional da informação. $O$ tratamento dos últimos dois tópicos, em especial, parece convocar a comunidade da área ao enfrentamento de novos desafios para que se possa fazer avançar a formação dos profissionais da área, focalizando certas particularidades da ação mediadora.

Nessa abordagem ganha revelo um objetivo implícito da mediação da informação: o desenvolvimento do protagonismo social. Por outro lado, ao se compreender a mediação como uma ação voltada ao protagonismo, até mesmo por ser dependente do processo dialógico como método possível para o estabelecimento da aproximação de pólos, observa-se que o sucesso da ação mediadora é também dependente do nível de concientização do agente dessa ação quanto ao seu próprio papel protagonista. O profissional da mediação da informação age, constrói e interfere no meio, portanto, é também um protagonista social, e nessa condição se constitui em sujeito da estética, da ética e da produção humanizadora do mundo.

Frente a isso, é urgente que sejam ampliados os estudos que aprofundem o debate em torno desses aspectos ligados à mediação da informação. Com o objetivo de ampliar essas reflexões, buscou-se neste texto apontar algumas considerações que emergiram da aproximação dos estudos de Damásio, Pareyson, Scherer e Larrosa, focalizados nas temáticas da consciência, estética, educação e ética, com abordagens já adotadas na literatura da área como as de autores como Freire, Vygostky, Almeida Junior, Bortolin, Peraya, Perrotti e Pieruccini.

Das reflexões em torno do pensamento desses autores foi possível observar contornos das dimensões dialógica, estética, formativa e ética da mediação da 
informação. Tais dimensões se apresentaram como aspectos a serem aprofundados nos estudos da área, de modo que se possa fazer avançar o aporte teórico que sustente novas experiências do fazer informacional no âmbito da ação mediadora do acesso, uso e apropriação a informação, voltada à formação do protagonismo social.

\section{REFLETINDO SOBRE O CARÁTER DIALÓGICO, ESTÉTICO, FORMATIVO E ÉTICO DA MEDIAÇÃO DA INFORMAÇÃO}

Toda experiência humana é dependente das práticas de comunicação, como também da transmissão cultural, que constituem o locus da mediação, envolvendo um processo de compartilhamentos objetivo e intersubjetivo por meio dos quais os sujeitos envolvidos nesse compartilhamento sempre geram significações. Por esta razão a ação mediadora é compreendida como uma ação essencialmente pautada na dialogia. Ainda que na ação mediadora estejam envolvidos sujeitos cujo grau de clareza acerca do processo limite essa compreensão e também o sucesso da ação, a dialogia sempre estará presente.

O processo dialógico possibilita a interlocutores distintos o encontro e a manifestação das subjetividades que emanam da interlocução inter e intrasubjetiva. $\mathrm{Na}$ mediação consciente, a dialogia torna exequível o exercício da crítica e a observação mais clara das incompletudes e lacunas que promovem a desestabilização dos conhecimentos estabilizados em cada sujeito. Ao mesmo tempo, o processo cooperativo e de "trocas" objetivas e subjetivas também é capaz de fazer com que seja acionada no sujeito desse processo o que Vygotsky (1998, $2001,2003,2003)$ denominou de zona de desenvolvimento proximal, entendida como uma instância potencializadora do desenvolvimento interior e da construção de sentidos, o que é imprescindível à apropriação da informação.

Para Vygotsky (1998) um elemento decisivo no desenvolvimento intelectual é a mediação, que o mesmo entende como ações realizadas no processo interacionista entre o sujeito, o objeto da aprendizagem, outros sujeitos envolvidos e o próprio meio onde a experiência se realiza, ressaltando assim a mediação como elemento essencial no processo de desenvolvimento intelectual.

Nessa perspectiva defende-se neste trabalho que a dialogia se situa na base da mediação. Um mediador consciente compreende que somente o processo dialógico torna bem sucedida a mediação pretendida. Isso também implica em se 
admitir que os sujeitos envolvidos nesse processo são singulares, podendo e devendo assumir o protagonismo da ação. Essa compreensão revela a mediação como um processo dialético que exige do agente mediador uma disposição e preparação para atuar no respeito a essa condição fundante da ação mediadora. E, ao mesmo tempo, ser capaz de se auto-avaliar, buscando seu auto-conhecimento para superação de seus próprios limites, mas também para se colocar como um sujeito implicado no processo, que se responsabiliza por ele, aperfeiçoando seu próprio perfil protagonista.

Ao se analisar a mediação na abordagem de Paulo Freire, observa-se ainda mais claramente o seu caráter potencializador da construção do protagonismo social. Freire $(2005,2008)$ defende a mediação como uma ação por meio da qual o homem pode se transformar em sujeito, já que na vivência do processo de mediação se pode refletir acerca da situação vivida, sobre seus interlocutores, sobre o mundo e sobre si mesmo, experiência que potencializa a formação da consciência que faz nascer o homem comprometido e capaz de intervir na realidade, enfim, capaz de se transformar em um protagonista e, simultaneamente, contribuir para a formação do protagonismo social.

Analisando-se a perspectiva do agente mediador da informação, daquele que medeia pólos (instâncias sociais, sujeitos sociais e dispsitivos culturais), compreende-se que este é também um protagonista, um protagonista do processo de mediação e, consequentemente, um protagonista social. Sua atuação se dá no encontro motivado por, mas também revelador de, necessidades, carências, desejos, limites, competências, experiências, saberes etc. Característica ainda mais relevante desse protagonismo a ser exercido pelo agente mediador está ligada ao caráter revelador do possível, e do aparentemente impossível, que a mediação bem sucedida pode proporcionar. Por meio dela, todos os sujeitos envolvidos na ação mediadora podem ter a oportunidade encontrar novas possibilidades $e$ potencialidades. A complexidade e, ao mesmo tempo, a humanidade que envolvem o processo de mediação demandam que se alcance maior clareza quanto à importancia da posição, disposição, responsabilidades e cuidados que precisam ser concientemente assumidos pelo agente mediador.

Se por um lado essa tomada de consciência quanto ao papel do mediador por parte daquele que atua no fazer informacional aponta para suas responsabilidades 
nesse processo, por outro também mostra suas próprias possibilidades enriquecedoras e potencializadoras da sua autorealização, da conquista do seu espaço como um protagonista social.

Por uma outra perspectiva, o desenvolvimento do auto-conhecimento, da consciência dos limites e potencialidades, do exercício da crítica e do enfrentamento dos desafíos que se apresentam, também aumentam a probabilidade do desenvolvimento de estratégias bem sucedidas de superação, do alcance da efetividade nas ações mediadoras e, consequentemente do encontro com a estética e a poética envolvidas no ato criador. Entendendo-se ambas na perspectiva de Baumgarten, sendo a estética considerada como a beleza do conhecimento sensível e a poética o discurso ou representação sensível do belo. (ABBAGNANO, 2000).

O encontro que se busca promover na ação mediadora entre aquele que necessita de informação e a informação pertinente é dependente do processo de comunicação, da adoção de linguagens e de dispositivos de comunicação, assim como do dominio dessas linguagens e dispositivos por parte do mediador, já que este é o agente de aproximação entre pólos e também aquele que deve promover o conhecimento e o dominio desses recursos por parte dos sujeitos envolvidos na ação mediadora. Nesse sentido, então, mais uma vez se pode refletir sobre a questão da estética.

Os sujeitos da ação comunicativa precisam transitar com "conforto" no "ambiente" do encontro, no espaço da interlocução, prencisam desenvolver o sentimento de pertença, já que o encontro promissor com a informação é aquele capaz de gerar o terreno propício para o desenvolvimento intelectual e a construção do conhecimento. E esse "conforto" se consolida a partir de uma base comunicacional dialógica, por meio da qual as ideias podem transitar sem censura ou rejeição e os debates sejam decorrentes do exercício da crítica e dependentes da interação paritária dos participantes da ação.

Pode-se assim dizer que a mediação da informação abriga uma comunicação centrada na relação dialógica, caracterizando-se como uma ação compartilhada e colaborativa, na qual o profissional da informação desempenha o papel de agente mediador, mas não representa o único agente desse processo de comunicação.

$\mathrm{Na}$ condição de mediador, o profissional da informação precisa também tornar-se apto a realizar a mediação do uso dos dispositivos de informação e 
comunicação que integram o cenário informacional. Tomando-se como referência Peraya (1999), entende-se mediação como uma ação que se desenvolve na articulação de dispositivos de natureza técnica, semiológica e pragmática. Na busca, no acesso e no uso da informação sempre há motivações de ordem pragmática e também ações e decisões pragmáticas. Há ainda a dependência do domínio de dispositivos tecnológicos, ambientais, instrumentais e técnicos, além das interações humanas e interações com os diversos dispositivos, interações estas geradoras do processo semiótico por meio do qual se produz sentidos.

A mediação da informação pressupõe técnicas, instrumentos, suportes, recursos, agentes e processos que, como entendem Perrotti e Pieruccini (2007), deixam de representar simples artifícios de transferência de conteúdos informacionais passando a se constituírem em dispositivos geradores de sentidos.

Dentro dessa abordagem, compreende-se a mediação como uma ação semiótica, dependente das diversas linguagens, e que para alcançar sucesso é também dependente da consciência de seus agentes de que todos os envolvidos na ação mediadora são interlocutores, portanto, também protagonistas do processo. Tais características da mediação colocam mais uma vez a sua dimensão estética em pauta, em especial por reafirmar a mediação como uma ação ligada ao movimento multidirecional, a um agir na vida, representando uma ação geradora de experiências a partir do encontro com a informação e com o outro (ou outros) que a produziram, promovem e disponibilizam, e ainda do encontro com os próprios dispositivos (instrumentos, processos, produtos, serviços, espaços e ambientes) que possibilitam a busca, o acesso e o uso da informação.

Scherer $(2005,2008)$, ao estudar os ambientes educacionais, virtuais e presenciais, defende a importância de se analisar a questão da estética nesses contextos educacionais, argumentando que a liberdade do movimento em direção ao conhecer, o prazer e o sentido do belo que se alcança na conquista da autonomia, traduzem uma estética que também se associa à estética dos próprios ambientes, o possibilita o estabelecimento de uma nova configuração do processo de aprendizagem em um contexto caótico de mudanças constantes, já que "inspira" confiança e conforto. Tomando-se as reflexões de Scherer $(2005,2008)$ como referência pode-se inferir que o mesmo ocorre com os ambientes de informação, que precisam ser compreendidos como ambientes estéticos, nos quais, e por meio 
dos quais, se estabelece a interlocução entre sujeitos que se expressam e se posicionam a partir de distintos lugares e perspectivas sócio-culturais.

Há na mediação da informação o sentido de compartilhamento, de cooperação, de abertura ao diálogo e ao movimento que desestabiliza e estabiliza conhecimentos, de abertura à crítica e à criatividade, de abertura também às intersecções entre o "velho" e o "novo", o que confere a ação mediadora certa característica de substrato ao autoconhecimento e ao entrelaçamento da humildade e da auto-estima dos interlocutores dessa ação. A promoção do transitar por essas "vias" confere beleza à mediação da informação e prazer a quem a experimenta, o que indica a sua dimensão estética.

Os sujeitos envolvidos no processo de mediação efetiva da informação sentem-se acolhidos e reconhecidos como participantes ativos, como protagonistas da informação. Nessa situação, emoções e sentimentos surgem no desenrolar da ação mediadora e precisam ser observados e considerados pelo mediador. Embora esses aspectos sejam de difícil alcance no cotidiano profissional, a escuta e a observação sensível podem favorecer a percepção das emoções e sentimentos que nascem ou se revelam na ação mediadora.

Conforme Damásio (2000), muito provavelmente a emoção surgiu no processo evolutivo, no esforço de sobrevivência gerador de soluções, antecedendo o aparecimento da consciência, emergindo em cada sujeito como resultado de indutores que, normalmente, não se identifica conscientemente. Enquanto 0 sentimento corresponde à experiência mental privada da emoção, esta última corresponde a um conjunto de reações passíveis de observação. (DAMÁSIO, 2000). Isso quer dizer que, enquanto não é possível observar diretamente os sentimentos de alguém, é possível observar os estados emocionais do outro. Além disso, 0 mediador pode observar seus próprios sentimentos, na medida em que, conscientemente, for capaz de observar os seus próprios estados emocionais. Assim, percebe-se que a base desse processo, tanto em termos intra quanto interpessoais, é dependente da ação consciente da busca do autoconhecimento e da disponibilidade para conhecer o outro, conhecer o meio e o contexto, o que acaba por colocar também em evidência a dimensão da ética.

Sendo a mediação da informação uma ação que envolve a interlocução entre sujeitos e a satisfação das necessidades informacionais, está em questão os 
sentimentos e emoções que mobilizam essa ação e dela são decorrentes. Como assinala Almeida Junior (2009), a mediação da informação representa uma ação de interferência, o que traz à tona a preocupação com a existência de uma relação tênue entre interferência e manipulação. No entanto, Almeida Junior (2009) argumenta que a consciência acerca da existência de uma realidade de interferência na ação mediadora, embora não assegure a eliminação da manipulação, pode significar a redução dos riscos de uma possível manipulação e de suas conseqüências.

A consciência e a competência para interferir evitando a manipulação são dependentes da conduta ética associada a busca de identificação de sinais que indiquem o grau de conforto, confiança, cumplicidade e cooperação que se pode gerar na ação mediadora. Isso implica no desenvolvimento de competências para acolher, ouvir e dialogar com o outro, implica na capacidade de escuta e observação sensíveis dos comportamentos que se desdobram da ação mediadora, além da adoção de princípios que inibam a censura e o direcionamento do acesso à informação que desconsidere a igualdade de direitos e a liberdade de pensamento.

Ao se admitir que a mediação da informação representa uma ação interacionista, na qual estão envolvidos fatores relacionados ao autoconhecimento, à consciência e à formação e valorização do protagonismo, inevitavelmente emerge a discussão em torno da ética, como instância valorizadora do coletivo, da ação e da conduta cuidadora e, portanto, balizadora da busca pela humanização do mundo.

As discussões em torno da ética se apresentam com maior força quando se admite que a mediação está ligada ao cuidar. Se a ação mediadora é uma ação ligada ao movimento e a vida, considerando-se que os sujeitos que necessitam de informação, e com os quais os profissionais da informação interagem, precisam sentir acolhimento, precisam desenvolver um sentimento de pertença ao ambiente informacional, então é preciso admitir que o mediador da informação é um agente envolvido com o ato de cuidar. Isso indica a necessidade de se incluir na agenda de pesquisa da Ciência da Informação estudos sobre a mediação da informação enquanto uma ação relacionada ao cuidado e aos aspectos psicológicos, estéticos e éticos que envolvem esse processo fundamental no trabalho com a informação.

A velocidade das mudanças tecnológicas no mundo contemporâneo também promovem alterações no processo de construção de sentidos, já que os dispositivos 
de mediação cultural são cada vez mais diversificados a coexistem nas práticas e relações sociais. Nesse contexto ocorrem alterações comportamentais e demandas inovadoras, o que exige ainda do profissional mediador da informação uma atenção especial quanto ao uso desses dispositivos, como também ao desenvolvimento constante das estratégias e programas de formação do usuário.

Ao abordar as atividades sistematizadas de formação do usuário como atividades de mediação se coloca mais uma vez em evidencia sua dimensão estética, mas também formativa e ética, que devem também integrar o conjunto de variáveis a serem analisadas no planejamento, execução e avaliação desse tipo de atividade de mediação.

Mesmo nas atividades de mediação não especificamente voltadas à formação de usuários, verifica-se um caráter formativo da ação mediadora e, portanto, uma forte relação com a estética e a ética. Pareyson (1993) trata da estética como uma "teoria da formatividade", entendendo que o ser humano enquanto sujeito que significa e ressignifica constantemente suas ações, encontra-se em processo permanente de formação, o que o coloca no sentimento de incomodo e de tensionamento constantes.

Na perspectiva da formatividade de Pareyson (1993), os sujeitos sociais estão em constante processo de formação, em razão da capacidade relacional do ser humano. Segundo o autor (1993), a formatividade é inerente a experiência porque toda formação ocorre na relação com outros e com o meio, num processo de mediação a partir do qual a experiância possibilita o aprender e a alteração do estágio intelectual, cognitivo e afetivo do sujeito.

Toda e qualquer atividade humana traz no seu âmago um caráter formativo porque está sempre ligada ao fazer, ao movimento, à ação, cuja operacionalização se dá através de um ato realizador de algo que, em certa medida acaba por inventar ou reinventar a ação e o sujeito da ação. Por outra perspectiva também observa-se que toda ação é motivada por experiências e só é concretizada na experiência. Desse modo, a experiência (o movimento inerente ao protagonismo) é condição imprescindível à mediação e à formação. Na experiência o sujeito se envolve e se implica, se entrega e se responsabiliza. Conforme Larrosa (2002) a experiência é tudo que se vivência, tudo que acontece ao sujeito, tudo que o toca e o afeta. Enfim, também se poderia acrescentar: tudo que mobiliza o sujeito. 
Compreendendo o universo formativo que envolve a mediação da informação se compreende com maior clareza quando Almeida Junior e Bortolin (2009) ressaltam que a mediação é uma ação de interferência do profissional da informação que tem por objetivo satisfazer uma necessidade informacional, ressaltando ainda que essa mediação pode se caracterizar como explícita ou implícita. Explicita quando a mediação é direta e, portanto, mais evidente porque ocorre nas relações diretas (presenciais ou virtuais) com os sujeitos que buscam a informação. Implícita quando a mediação é indireta e menos evidente por se relacionar a ações de representação, organização, e demais atividades meio que, enfim, se caracterizam como ações intermediárias das relações diretas com os usuários reais e potenciais dos ambientes de informação.

$\mathrm{Na}$ mediação direta há maiores possibilidades de se observar o caráter estético, ético e formativo do fazer informacional. Entretanto, no caso da mediação indireta da informação essas questões parecem adentrar numa condição subliminar, dificultando a compreensão da sua natureza mediadora e, portanto, também das suas dimensões estética, ética e formativa. Mas, pode-se e deve-se avançar no sentido de desvelar toda a riqueza mediadora do fazer informacional em todas as suas instâncias.

\section{CONSIDERAÇÕES FINAIS}

Considerando que o objetivo implícito da mediação da informação consiste no desenvolvimento do protagonismo social e que esta é dependente do processo dialógico, conclui-se que a mediação representa uma ação também dependente do nível de concientização do agente que a realiza em relação a esse objetivo, como também quanto ao seu papel protagonista, que nessa condição interfere no meio e se constitui em sujeito da estética, da ética e da humanização do mundo.

A ação mediadora, compreendida como essencialmente pautada na dialogia que possibilita o encontro e a manifestação das subjetividades que emanam da interlocução inter e intrasubjetiva. Quando a mediação é consciente, a dialogia assegura o exercício da crítica e torna mais evidente as incompletudes e as lacunas que provocam a desestabilização dos conhecimentos já estabilizados no sujeito. Sendo assim, percebe-se que o processo dialético é uma condição fundante da ação 
mediadora, que demanda do mediador da informação a abertura e a capacidade de auto-avaliação na busca do seu auto-conhecimento e superação dos próprios limites, colocando-se no processo como um sujeito implicado, que se responsabiliza pelo sucesso da ação mediadora, mas também pelo aperfeiçoando do seu próprio protagonismo.

Dentro dessa abordagem, compreende-se a mediação como uma ação semiótica, dependente das diversas linguagens e da consciência de que todos os envolvidos na ação são interlocutores e protagonistas do processo, que guarda uma dimensão estética por se tratar de uma ação ligada ao movimento e geradora de experiências a partir do encontro com a informação e com os sujeitos que a produzem, promovem e disponibilizam, assim como com os dispositivos que possibilitam a busca, o acesso e o uso da informação.

O movimento em busca da informação para ampliar o conhecer pode gerar o prazer e o sentido do belo, quando contemplado pela conquista da autonomia, construída a partir da efetividade da ação mediadora, traduzindo uma estética que também pode estar associada à estética dos próprios ambientes, do discurso e abordagens do mediador e dos instrumentos, produtos e serviços acessados nesse ambiente.

Há na mediação da informação o sentido de compartilhamento, de cooperação, de abertura ao diálogo e ao movimento e ao exercício da crítica que gera criatividade, portanto, esta ação guarda ainda uma dimensão formativa. Ao transitar por essas "vias" com conforto e confiabilidade os sujeitos envolvidos sentem-se acolhidos como participantes ativos, como protagonistas da informação e, consequentemente, sentem o prazer dessa experiência e do aprendizado, o que confere beleza à mediação da informação, indicando a existência das suas dimensões estética e formativa. Considerar as dimensões estéticas e formativas da mediação da informação coloca o agente mediador frente ao desafio de desenvolver a escuta e a observação sensível, buscando alcançar a percepção das emoções e sentimentos que emergem no processo de mediação, o que também revela sua dimensão ética.

Numa outra perspectiva, quando se considera a mediação da informação como uma ação de interferência, que traz implicitamente uma preocupação com o risco da manipulação da informação e da interlocução, a dimensão ética da ação 
mediadora é mais uma vez evidenciada, o que reclama pelo desenvolvimento da consciência e competência para uma interferência sem manipulações, garantindo o acolhimento, a escuta, a observação e o diálogo com os envolvidos na ação, como também o direito de acesso a diversidade de ideias e o livre pensar, inibindo a censura e o tratamento desigual.

A dimensão ética da mediação da informação se revela com maior intensidade quando se constata a sua ligação com o movimento e a vida dos sujeitos que necessitam de informação e precisam sentir-se acolhidos para desenvolver um sentimento de pertença ao ambiente informacional. E, no seu conjunto, todas as dimensões aquí abordadas indicam que a mediação da informação se caracteriza como um ato do cuidar, sendo, portanto, uma ação relacionada a aspectos psicológicos, estéticos e éticos que envolvem o trabalho com a informação. Nesse diapasão a Ciência da Informação poderá avançar em suas discussões em torno da mediação da informação, formulando bases sólidas ao aperfeiçoamento do trabalho informacional.

\section{REFERÊNCIAS}

ABBAGNANO, Nicola. Dicionário de Filosofia. São Paulo: Martins Fontes, 2000. p. 768.

ALMEIDA JÚNIOR, Oswaldo Francisco. La mediación de la información y la lectura informacional. In: GARCIA MARCO, Francisco Javier (Org.). Avances y perspectivas en sistemas de información y documentación. Zaragoza: Universidad de Zaragoza, 2009. p. 23-28.

ALMEIDA JÚNIOR, Oswaldo Francisco de; BORTOLIN, Sueli. Mediação da informação e da leitura. In: SILVA, Terezinha Elisabeth da (Org.).

Interdisciplinaridade e transversalidade em Ciência da Informação. Recife: Néctar, 2008, p.67-86.

DAMÁSIO, A. O mistério da consciência. São Paulo: Companhia das Letras, 2000.

FREIRE, Paulo. Pedagogia do oprimido. 43. ed. Rio de Janeiro: Paz e Terra, 2005.

FREIRE, Conscientização: teoria e prática da libertação: uma introdução ao pensamento de Paulo Freire. São Paulo: Centauro, 2008.

LARROSA, J. Nietzsche \& a educação. Belo Horizonte: Fundação Biodiversitas: Autêntica, 2002. 
PAREYSON. Luigi. Estética: teoria da formatividade. Petrópolis: Vozes, 1993.

PERAYA, Daniel. Médiation et médiatisation: le campus virtuel. Hermès, Paris, $\mathrm{n}$. 25, 1999. Disponível em: <http://documents.irevues.inist.fr/handle/2042/14983>. Acesso em: 25 jun. 2010.

PERROTTI, Edmir; PIERUCCINI, Ivete. Infoeducação: saberes e fazeres da contemporaneidade. In: LARA, Marilda L. Ginez de; FUJINO, Asa; NORONHA, Daisy P. (Orgs.). Informação e contemporaneidade: perspectivas. Recife: Néctar, 2007. p. 47-96.

SCHERER, S. Uma estética possível para a educação bimodal: aprendizagem e comunicação em ambientes presenciais e virtuais. 2005. 241 f. Tese (Doutorado em Educação) - Pontifícia Universidade Católica, São Paulo, 2005.

SCHERER, S. Comunidades virtuais de aprendizagem: habitantes, visitantes e transeuntes. In: CONGRESSO DA ASSOCIAÇÃO BRASILEIRA DE EDUCAÇÃO A DISTÂNCIA - ABED, 2008. Disponível em: <http://www.abed.org.br/congresso2008/tc/511200835743PM.pdf>. Acesso em: 13 mar. 2013.

VYGOTSKY, L. S. A formação social da mente. 6. ed. São Paulo: Martins Fontes, 1998.

VYGOTSKY, L. S. Obras escogidas. 2. ed. Madrid: A. Machado Libros, 2001.

VYGOTSKY, L. S. Pensamento e linguagem. São Paulo: Martins Fontes, 2003.

VYGOTSKY, L. S. Psicologia pedagógica. Edição comentada. São Paulo: Artmed, 2003.

\section{Title}

Dialogical, aesthetics, formative and ethic dimension of information mediation

Abstract

Introduction: Discusses information mediation from its implicit goal of working in the development of social leadership.

Objective: Expand the debate and reflections on the dialogical, aesthetics, education, and ethics dimensions of information mediation.

Methodology: It is characterized as a bibliographical study from the association of studies that focus on thematic conscience, aesthetics, education, and ethics, with other adopted in literature to treat information mediation.

Results: The dialogical, aesthetics, formative and ethics dimensions of information mediation seeking to expand the debate and reflections on the, which are presented as thematic topics among deeper studies of the area. 
Conclusion: The information mediation is characterized as a dependent action of the dialogical process and the level of conscientization of the mediator as to his own leading role. Thus, the study of these dimensions can advance the theoretical basis for the development of new experiments in mediating action of access, use and ownership at information, spotted on the formation of social leadership.

Key words: Information mediation - Aesthetics. Information mediation - Ethics. Information mediation - User education. Information mediation - Dialogism.

\section{Título}

Dimension dialógica, estética, formativa y ética de la mediación de la información

\section{Resumen}

Introducción: Discute la mediación de la información desde su meta implícita de trabajar en el desarrollo del liderazgo social.

Objetivo: Ampliar el debate y la reflexión sobre las dimensiones dialógica, estética, de formación y ética en la mediación de la información.

Metodología: Estudio bibliográfico de la combinación de las obras que se centran en la temática de la conciencia, la estética, la educación y la ética, con el ya adoptado en la literatura para el tratamiento de la mediación de la información.

Resultados: Las dimensiones dialógica, estética, de formación y ética en la mediación de la información se presentan como ejes temáticos para estudios más profundos de el área científica.

Conclusión: La mediación de la información se caracteriza como una acción dependiente del proceso de diálogo y del nivel de concientización del mediador en cuanto a su propio papel protagonista. Por lo tanto, el estudio de estas dimensiones puede ampliar la base teórica para el desarrollo de nuevos experimentos en la mediación de la acción de acceso, uso y apropiación de la información, centrado en la formación de liderazgo social.

Palabras-clave: Mediación de la información - Estética. Mediación de la información - Ética. Mediación de la información - Educación del usuario. Mediación de la información - Dialogismo.

Recebido em: 15.07.2014

Aceito em: 05.10.2014 